\title{
Impact of family-related factors on mental health and adjustment of adolescents
}

\author{
Rajkumar Gajendran', Sivabalan Thiruvannamalai ${ }^{2}$ \\ From ${ }^{1}$ Professor, ${ }^{2}$ Assistant Professor, Department of Paediatrics, Dhanalakshmi Srinivasan Medical College and Hospital, Perambalur, Tamil Nadu, \\ India
}

Correspondence to: Dr. Sivabalan Thiruvannamalai, Department of Paediatrics, Dhanalakshmi Srinivasan Medical College and Hospital, Perambalur - 621 212, Tamil Nadu, India. E-mail: tshiva_79@yahoo.co.in

Received - 17 June $2019 \quad$ Initial Review - 07 July 2019

Accepted - 15 July 2019

\begin{abstract}
Background: Adolescence is believed to be a period of great stress and storm, as rapid physical and mental changes occur during this period with a lot of problems in adjustment of children. Objective: The objective of this study was to assess the impact of familyrelated factors on mental health and adjustment in adolescents. Materials and Methods: This is a cross-sectional study involving 175 school-going boys and girls of age 14-17 years. The students were administered a sociodemographic pro forma, general health questionnaire-28 (GHQ-28), and adjustment inventory for school students (AISS) by one-to-one interview method. Family-related factors such as maternal education and occupation, relationship of the primary caregiver, type of family, and number of siblings were analyzed with the scores of GHQ and AISS by Student's Mann-Whitney U-test and Kruskal-Wallis test using the SPSS 20.0. Results: Poorer maternal education is associated with greater anxiety and insomnia than those of mothers with better education $(\mathrm{p}=0.008)$, while maternal occupation had a negative impact on overall adjustment scores $(\mathrm{p}<0.0001)$. Children from nuclear family and children reared by grandparents showed significantly greater social dysfunction $(p<0.0001)$. Emotional adjustment, educational adjustment, and overall adjustment scores were significantly higher in children from nuclear family. Significant increase in the educational adjustment scores is seen in children brought up by parents. Social dysfunction was more among students who had two siblings when compared to children with one sibling $(\mathrm{p}=0.01)$. Conclusion: Family-related factors significantly affect the mental health and coping nature of the adjustment-related problems.
\end{abstract}

Key words: Adjustment, Adolescence, Family-related factors, Mental health, Students

A dolescence not only brings transformation in the physique but also in the knowledgeable form. These above fluctuations have noteworthy ups and downs on mental functioning. Adjustment depends on one's own health, wealth, home, family, and school, social, and personal life. These influences are at random and differ from each other in different situations. A child's attitude toward his own life, his family members, and other objects is developed during his early life through his interactions within his own family followed by his contacts with peers. This is the early period of his social development which determines his adjustment in future with different people and situations. There is ample evidence to suggest that children brought up in liberal families are found in later life more successful in their adjustment in varied situations. On the other hand, children belonging to restrictive families are likely to be more dependent, obedient, non-creative, less dominant, and comparatively more polite and submissive [1-7].

The adjustment inventory for school students (AISS) [8] designed by Sinha and Singh is a self-report inventory which seeks to segregate well-adjusted secondary school students (age group 14-18 years) from poorly adjusted students in the three areas of adjustment - emotional, social, and educational domains.
The inventory consists of 60 items, 20 items for each area of adjustment.

The general health questionnaire-28 (GHQ-28) [9] is used to detect psychiatric disorder in the general population and within community or non-psychiatric clinical settings such as primary care or general medical outpatients. It assesses the respondent's current state and asks if that differs from his or her usual state. It is, therefore, sensitive to short-term psychiatric disorders but not for long-standing attributes of the respondent. The present study was aimed at exploring the family-related factors influencing the adjustment problems and to correlate them with the mental health of secondary school students.

\section{MATERIALS AND METHODS}

This is a descriptive, cross-sectional study involving 175 school students of both genders and of age ranging from 14 to 17 years. The study was started after getting clearance from the institutional ethics committee. The study participants were recruited from both government and private schools using convenient sampling method after getting consent from their parents and permission from their school principals. Students, who were on treatment for 
any proven psychological or psychiatric disorder or having any long-term medications, were excluded from the study.

After a brief introduction by the investigator, the students were asked to fill the sociodemographic pro forma. The students were made to answer for GHQ-28 and AISS on one-to-one interview method after clearly understanding the meaning of questions. It was also emphasized that there were no right or wrong answers.

\section{Scoring of GHQ-28}

The four subscales, each containing seven items, are as follows: A - Somatic symptoms (items 1-7); B - anxiety/insomnia (items 8-14); C - social dysfunction (items 15-21); and D - severe depression (items 22-28). For identifying caseness with GHQ28 , the total of the subscales is used. GHQ scoring (0-0-1-1) for positive items, where agreement indicates health, and 0-1-1-1 for negative items, where agreement indicates illness. The higher the score, the more severe is the condition.

\section{Scoring of AISS}

The total score on adjustment is obtained by adding the individual domain scores, which indicate the general adjustment status.

After collection of the data, results were analyzed using Mann-Whitney U-test and Kruskal-Wallis test using the SPSS 20.0

\section{RESULTS}

Table 1 shows the percentage analysis of the baseline characteristics and sociodemographic details of the 175 study participants. The participants have been categorized based on maternal education and occupation, type of family, primary caretaker, and number of siblings.

Table 2 shows the GHQ and adjustment scores in relation with maternal education using Kruskal-Wallis test. The level of maternal education was significantly associated with social dysfunction in GHQ, with children of mothers with poorer education having greater social dysfunction than those of mothers with better education $(\mathrm{p}=0.008)$, while the level of maternal education was not significantly associated with adjustment.

Table 3 shows relationship between maternal occupation and adjustment scales. This analysis was done using Mann-Whitney U-test. In our study, we found a negative effect of maternal occupation on adjustment scores.

Table 4 shows the GHQ and adjustment scores in relation with family type, type of caregiver, and number of siblings. Children from nuclear family and children reared by grandparents showed significantly greater social dysfunction $(p=0.0001)$. This study also showed that that emotional adjustment and the overall score for adjustment are greater in children from nuclear family ( $\mathrm{p}=0.04,0.01$, and 0.02 , respectively).

Educational adjustment scores were significantly higher in children from nuclear family, reared by parents, and with single
Table 1: Sociodemographic details of the study participants

\begin{tabular}{lc}
\hline Characteristics & $\mathbf{n}(\mathbf{\%})$ \\
\hline Age & $49(28)$ \\
14 & $39(22.3)$ \\
15 & $49(28)$ \\
16 & $38(21.7)$ \\
17 & \\
Gender & $90(51.4)$ \\
Boys & $85(48.6)$ \\
Girls & \\
Mother's occupation & $123(70.3)$ \\
Unemployed & $52(29.70$ \\
Employed & \\
Family type & $122(69.7)$ \\
Nuclear & $53(30.3)$ \\
Joint & \\
Primary caretaker & $133(76)$ \\
Parents & $42(24)$ \\
Grandparents & \\
Number of siblings & $143(81.7)$ \\
One sibling & $32(18.2)$ \\
More than one sibling &
\end{tabular}

Table 2: GHQ and adjustment scores in relation with maternal education

\begin{tabular}{lcccc}
\hline Type of scale & $\begin{array}{c}\text { Middle } \\
\text { school } \\
\mathbf{n = 9}\end{array}$ & $\begin{array}{c}\text { High } \\
\text { school } \\
\mathbf{n = 3 6}\end{array}$ & $\begin{array}{c}\text { High school } \\
\text { diploma } \\
\mathbf{n = 4 8}\end{array}$ & $\begin{array}{c}\text { Graduate/ } \\
\text { postgraduate } \\
\mathbf{n = 8 0}\end{array}$ \\
\hline $\begin{array}{l}\text { GHQ_anxiety } \\
\text { insomnia }\end{array}$ & $2.0 \pm 0.00$ & $1.89 \pm 0.319$ & $1.77 \pm 0.425$ & $1.84 \pm 0.371$ \\
\hline p=0.008; highly significant by Kruskal-Wallis test, GHQ: General health questionnaire
\end{tabular}

Table 3: Relationship between maternal occupation and adjustment scales

\begin{tabular}{lccc}
\hline Type of scale & $\begin{array}{c}\text { Unemployed } \\
\mathbf{n = 1 2 2}\end{array}$ & $\begin{array}{c}\text { Employed } \\
\mathbf{n = 5 3}\end{array}$ & p value \\
\hline AISS_emotional adjust & $3.67 \pm 0.875$ & $3.98 \pm 0.754$ & $0.02^{*}$ \\
AISS_social adjust & $3.70 \pm 0.689$ & $4.08 \pm 0.652$ & $0.001^{*}$ \\
AISS_education adjust & $4.13 \pm 0.768$ & $4.50 \pm 0.577$ & $0.002^{*}$ \\
AISS_overall score & $3.81 \pm 0.684$ & $4.25 \pm 0.480$ & $0.0001^{*}$ \\
\hline
\end{tabular}

AISS: Adjustment inventory for school students, ${ }^{*} \mathrm{p}=0.02$

sibling ( $\mathrm{p}=0.01,0.009$, and 0.05$)$. Emotional adjustment scores were higher in children from nuclear family $(p=0.04)$.

\section{DISCUSSION}

Adolescence is a period which challenges the individual for the changes occurring in them, both physically and mentally. Smooth transit through adolescence and coping of all the challenges depends on multiple factors at home, school, and surrounding environment. They are expected to strive to attain mature relations with age mates, learn to perform appropriate gender roles, ascertain autonomy, prepare for economic independence, 
Table 4: Mean scores of GHQ and AISS parameters classified by type of family, caregiver, and number of siblings

\begin{tabular}{|c|c|c|c|c|c|c|}
\hline \multirow{2}{*}{$\begin{array}{l}\text { GHQ and AISS } \\
\text { category }\end{array}$} & \multicolumn{2}{|c|}{ Type of family } & \multicolumn{2}{|c|}{ Caregiver } & \multicolumn{2}{|c|}{ Number of siblings } \\
\hline & Nuclear $(n=122)$ & Joint $(n=53)$ & Parents $(n=133)$ & Grandparents $(n=41)$ & One $(n=143)$ & $>1(n=32)$ \\
\hline GHQ_social dysfunction & $1.11 \pm 0.32$ & $1.38 \pm 0.48^{*}$ & $1.12 \pm 0.32$ & $1.44 \pm 0.50 *$ & $1.17 \pm 0.37$ & $1.39 \pm 0.49 *$ \\
\hline GHQ_anxiety-insomnia & $1.80 \pm 0.39$ & $1.89 \pm 0.32$ & $1.83 \pm 0.38$ & $1.85 \pm 0.35$ & $1.80 \pm 0.39$ & $1.96 \pm 0.20 *$ \\
\hline AISS_education adjust & $4.33 \pm 0.69 *$ & $4.04 \pm 0.78$ & $4.32 \pm 0.70^{*}$ & $3.98 \pm 0.79$ & $4.27 \pm 0.72 *$ & $3.96 \pm 0.76$ \\
\hline AISS_emotional adjust & $3.84 \pm 0.86^{*}$ & $3.57 \pm 0.79$ & $3.80 \pm 0.84$ & $3.61 \pm 0.86$ & $3.73 \pm 0.86$ & $3.87 \pm 0.75$ \\
\hline AISS_overall score & $4.02 \pm 0.68^{*}$ & $3.77 \pm 0.57$ & $4.00 \pm 0.64^{*}$ & $3.78 \pm 0.69$ & $3.96 \pm 0.66$ & $3.82 \pm 0.66$ \\
\hline
\end{tabular}

Statistical analysis done by Mann-Whitney U-test. * - statistically significant; $p$ values are mentioned in text under results section, GHQ: General health questionnaire, AISS: Adjustment inventory for school students

make decisions on intimate relationships, and aspire to be responsible in community and to develop a set of values or morals. Family, friends, and peers have a great role during this transition period [1-6].

The present study revealed that there were adjustment and general mental health problems among school-going adolescents mostly significant. Level of maternal education was significantly associated with social dysfunction in GHQ with children of mothers with poorer education having greater social dysfunction than those of mothers with better education. Anand [10], in their study, found that students with parents of better educational and occupational backgrounds had better mental health. Rahi et al., 2005 [11], also showed that maternal education is significantly associated with psychopathological disorders in children and also the prevalence of disorders was highest in the offsprings of illiterate mothers.

The present study showed that the level of maternal education was not significantly associated with adjustment in children which is in accordance with the study done by Nagarajan [12] and Felner et al. [13] revealed that youth from families, in which neither parent had graduated exhibited significantly worse socioemotional and academic adjustment compared to the youth from graduated families. Studies by Douvan et al. [14] and Gold and Andres [15] found negative effect of mother's occupation on adjustment in boys while Nelson reported its positive effect in girls [16]. This poor adjustment may be due to lack of emotional bonding between working mother and children and overexpectation and pressure. Reeta and Anuradha [17] in their study also proved that adolescents with both parents working faced more problems than the adolescents with mother working part time or housewife. Sinha and Singh [8] using the self-developed adjustment inventory found that girls of non-employed mothers adjusted significantly well than those of employed mothers and no difference was found among the boys of employed and non-employed mothers.

The current study showed that children from nuclear family have greater social dysfunction when compared to those from joint family. Furthermore, it was evident that emotional adjustment, educational adjustment, and overall adjustment scores were significantly higher in children from nuclear family. This implies that children from nuclear family showed poorer adjustment than those from joint family. This finding was supported by Emmanuel [18].

It was proven from our study that children reared by grandparents showed significantly greater social dysfunction than who are reared by parents. On the contrary, our study showed a significant increase in the educational adjustment scores and near significance of overall adjustment scores in children brought up by parents implying that children brought up by parents showing poorer adjustment. This may be due sharing of responsibility in the case of multiple caretakers.

Oliva and Arranz [19] studied a sample of 513 adolescents aged between 13 and 19 years and concluded that in girls with good sibling relationship, having siblings were related to adolescent's social and personal adjustment. In cases of poor sibling adjustment, it was the negative effects of everyday situations of rivalry and conflict which outweighed the benefits of any support that was provided. Our study clearly showed that anxiety symptoms and social dysfunction were more among students who had two or more siblings than the students with one sibling. Students with more number of siblings showed more anxiety symptoms and poor social dysfunction while they showed better educational adjustment compared to those with less number. This was in accordance with the studies done by Oliva and Arranz [19] and Rajeswari [20]. The study was limited by its small sample size.

\section{CONCLUSION}

The current study clearly shows that factors such as poorer maternal education, children grown by grandparents, and those with two or more siblings have higher incidence of social dysfunction. Children with working mothers and grown in nuclear families are associated with poorer adjustment. Further, elaborate studies with greater sample are necessary to validate these results.

\section{REFERENCES}

1. Conger KJ, Conger RD, Scaramella LV. Parents, siblings, psychological control and adolescent adjustment. J Adolesc Res 1997;12:113-38.

2. Drotar D. Relating parent and family functioning to the psychological adjustment of children with chronic health conditions: What have we learned? What do we need to know? J Pediatr Psychol 1997;22:149-65.

3. Roychaudhary P, Basu J. Parent-child relationship, school achievement and adjustment of boys. J Community Guid Res 1998;15:215-26.

4. Scott WA, Scott R. Family correlates of high-school student adjustment: A cross-cultural study. Aust J Psychol 1989;41:269-84.

5. Srivastava RK. Family structure, manifest anxiety and disclosure of self among urban boys. Psychol Stud (Mysore) 1984;29:169-71.

6. Varni JW, Katz ER, Colegrove R Jr., Dolgin M. Family functioning predictors of adjustment in children with newly diagnosed cancer: A prospective analysis. J Child Psychol Psychiatry 1996;37:321-8. 
7. Werner NE, Silbereisem RK. Family relationship quality and contact with deviant peers as predictors of adolescent problem behaviours: The moderating role of gender. J Adolesc Res 2003;18:454-80.

8. Sinha AK, Singh RP. Adjustment Inventory for School Students. Agra: National Psychological Corporation; 1971.

9. Goldberg D, Williams P. A User's Guide to the General Heath Questionnaire. Windsor: NFER-Nelson; 1988.

10. Anand SP. A study of student's mental health attitude and motivation for studies. J Educ Res Extn 1999;36:55-61.

11. Rahi M, Kumavat AP, Garg S, Singh MM. Socio-demographic co-relates of psychiatric disorders. Indian J Pediatr 2005;72:395-8.

12. Nagarajan J. Astudy on Adjustment Behaviour, Self-Acceptance and Frustration of Secondary School Students in Kanchipuram Educational District. Abstract Number, SRWES: 072. It is a Dissertation Submitted to SRM University for M. Phil in the Year; 2012.

13. Felner RD, Brand S, Dubois DL, Adan AM, Mulhall PF, Evans EG. Socioeconomic disadvantage, proximal environmental experiences, and socio emotional and academic adjustment in early adolescence: Investigation of a mediated effects model. Child Dev 1995;66:774-92.

14. Douvan EA, Douvan E, Adelson J. The Adolescent Experience. New York: John Wiley and Sons; 1966.

15. Gold D, Andres D. Maternal employment and development of 10 year old
Canadian francophone children. Can J Behav Sci 1980;12:233-40.

16. Nelson DD. A study of personality adjustment among adolescent children of working and non-working mothers. J Educ Res 1971;62:328-30.

17. Reeta S, Anuradha J. Problems of adolescence: Impact of working women and gender differences variables. Ind Psychol Rev 1994;42:8-12.

18. Emmanuel D. Adjustment among school going adolescents: A study in Kunnathur village, Annur block (Coimbatore district). Int J Humanit Soc Sci Invent 2013;2:7-12.

19. Oliva A, Arranz E. Sibling relationships during adolescence. Eur J Dev Psychol 2005;2:253-70.

20. Rajeswari S. A study on emotional adjustment of adolescent school students. Int J Humanit Soc Sci 2013;2:49-56.

Funding: None; Conflict of Interest: None Stated.

How to cite this article: Gajendran R, Thiruvannamalai S. Impact of familyrelated factors on mental health and adjustment of adolescents. Indian J Child Health. 2019; 6(7):388-391.

Doi: 10.32677/IJCH.2019.v06.i07.014 